\title{
Selective predation by reintroduced juvenile Lake sturgeon (Acipenser fulvescens) in Ft. Loudoun reservoir, Tennessee (USA)
}

\author{
Todd M. Amacker • J. Brian Alford
}

Received: 5 January 2017 / Accepted: 19 July 2017 /Published online: 8 August 2017

(C) The Author(s) 2017. This article is an open access publication

\begin{abstract}
Following water quality and minimum flow improvements to the impounded Tennessee and Cumberland Rivers, juvenile lake sturgeon (Acipenser fulvescens) have been restocked annually since 2000 . Our goal was to seasonally assess foraging mode of this recovering population in Ft. Loudoun Reservoir in the Upper Tennessee River. During 2014-15, individuals were captured using trot-lines in a $13-\mathrm{km}$ reach that supports the greatest density of lake sturgeon. We used colonic flushing and gastric lavage techniques to obtain diet. We took systematic benthic sediment grabs along multiple transects throughout the reach and opportunistically deployed rock cages filled with hard substrates to assess potential prey that colonize hard surfaces. Foraging modes of lake sturgeon were determined by comparing relative abundances of invertebrate taxa in the gut contents (6581 invertebrates) of 28 fish to the relative abundances of the same invertebrate taxa collected from the resource base (1667 invertebrates). Proportional similarity, Levin's niche breadth, and Manly's index were used to assess the degree of prey selectivity. Lake sturgeon fed selectively on a narrow range of available prey consisting mostly of larval chironomids (93\% composition by number during warm season, $96 \%$ during cool season), some genera of which they prey upon
\end{abstract}

T. M. Amacker · J. B. Alford $(\bowtie)$

Institute of Agriculture, Department of Forestry, Wildlife, and Fisheries, The University of Tennessee, 274 Ellington Plant

Sciences Bldg., Knoxville, TN 37996, USA

e-mail: jalfor12@utk.edu selectively, primarily Chironomus sp., but to a lesser extent Procladius, Ablabesmyia, Coelotanypus, and Cryptochironomus spp. Meanwhile, other abundant taxa in the resource base were avoided, such as Oligochaetes, Hexagenia mayflies, and the chironomid Glyptotendipes. Our results illustrate that assessing seasonally available prey from habitat utilized by lake sturgeon is important when investigating diet preference.

Keywords Chironomidae $\cdot$ Foraging $\cdot$ Diet $\cdot$ Niche $\cdot$ Proportional similarity

\section{Introduction}

The lake sturgeon (Acipenser fulvescens) was once common in the Great lakes, Mississippi River, and Hudson River drainages of the United States and Canada (Peterson et al. 2007). The mechanisms for their decline are well-documented and anthropogenic in nature, including overharvest, habitat fragmentation, and habitat degradation (Pollock et al. 2015). Currently imperiled across much of their range, rehabilitation efforts have been employed to enhance recovery (Haxton 2011) and assessments have been made of stock size, available spawning habitat, and factors affecting spawning success (Peterson and Vecsei 2004). Though many anthropogenic factors continue to impede restoration and conservation initiatives, lake sturgeon populations in the Northern U.S. and Southern Canada have maintained relatively robust populations due to remnant spawning 
stocks, enhancement stocking efforts, and restoration of spawning habitats (Drauch and Rhodes 2007; Bezold and Peterson 2008).

In stark contrast, the Southeastern U.S. has relied heavily on intensive stocking efforts, with most native populations being extirpated by the 1970s from overharvest, inadequate dam operations, and pollution (Bezold and Peterson 2008). As water quality and minimum flows from dam operations improved (Higgins and Brock 1999), conditions were considered appropriate for reintroduction of the federally threatened lake sturgeon to the Tennessee River and Cumberland River (Tennessee River drainage) as well as the Coosa River (Mobile River drainage). Stocking began in 2000 (SLSWG 2013), with fertilized eggs coming from the Lake Winnebago population in Wisconsin (USA) managed by the Wisconsin Department of Natural Resources and the U.S. Fish and Wildlife Service (USFWS). Each spring, larvae are reared by the USFWS at the Warm Springs National Fish Hatchery, Georgia, and stocked into the Tennessee, Cumberland, and Coosa Rivers during October-November of the same year at a minimum size of $18 \mathrm{~cm}$ total length (TL). Subsequent studies investigating the stock status, ecology, and behavior of the reintroduced population have only just begun. Unlike the well-studied northern U.S. and Canadian populations, there are several aspects of lake sturgeon ecology and management that scientists in the Southeastern U.S. have yet to address. One such research need is an assessment of diet and prey availability of reintroduced, juvenile lake sturgeon residing in the impounded portions of the Upper Tennessee River basin where most of the stock congregates (SLSWG 2013). Due to lower latitudes and the serially impounded environment of the Upper Tennessee River, it is likely that food availability will be different than that found in the northern reaches of the lake sturgeon's range. This study does not address foraging ecology of the native genetic stock of lake sturgeon that historically occurred here; however, it does provide information on the dietary habitats of a recovering population in a highly regulated environment such as the main stem Tennessee River system.

Lake sturgeon are most accurately referred to as supra-benthic cruisers (Peterson and Vecsei 2004), because they are not a truly benthic fish. However, they do feed primarily on benthic invertebrates and rely heavily on tactile, olfactory, chemosensory, and electrosensory receptors to locate them (Harkness and Dymond 1961). Feeding occurs as a fish sweeps the benthos while keeping its barbels in contact with the substrate. When a prey item is detected, suction is used to capture the prey by rapidly extending their protrusible mouth and creating a negative pressure gradient in the buccal cavity by closing the suboperculum during suction and swallowing prey whole (Peterson and Vecsei 2004). Though lake sturgeon inhabit a variety of substrate types, prey availability (quantity and quality) is undoubtedly an important factor in determining habitat selection (Harkness and Dymond 1961).

Food quantity and quality as well as temperature are the main factors influencing the bioenergetics of fishes (LeBreton and Beamish 2005). Thus, quantitative assessment of diet is an important aspect of fisheries management (Chipps and Garvey 2007), and managing prey resources is vital in conserving threatened or endangered fish (Finnoff and Tschirhart 2003). Accurate descriptions of fish diets and feeding patterns not only help to assess habitat utilization and growth, but also outline trophic interactions in large river ecosystems (Vander Zanden et al. 2000). Compared to wadeable streams, marine and estuarine habitats, which are rich in benthic invertebrate resources, deep riverine systems and reservoirs where lake sturgeon spend the entirety of their lives tend to be less rich (Vannote et al. 1980). Understanding the availability of prey items in the impounded Tennessee River system can help managers better understand how lake sturgeon are faring in their newly reclaimed environment.

Although Harkness (1923) initially reported that lake sturgeon from Ontario, Canada consumed crayfish, mollusks, immature insects, fish eggs, fishes (rarely), nematodes, leeches, amphipods, and decapods, a more detailed study of lake sturgeon diet in the Upper Tennessee River Basin is of considerable importance, because significant differences in geographic range can yield different results. Additionally, there is concern that a reintroduced benthic predator may negate efforts to conserve threatened and endangered mussel species that once thrived in the Tennessee, Cumberland and Coosa River systems. Our objectives were to 1) identify the seasonally available benthic prey base for reintroduced juvenile lake sturgeon in Ft. Loudoun Reservoir 2) describe diet composition from stomach and intestinal contents and 3) determine whether juvenile lake sturgeon in Ft. Loudoun Reservoir forage selectively or opportunistically on seasonally available benthic invertebrates. 


\section{Materials and methods}

Study area

The portion of the Tennessee River between Knoxville, TN and Chattanooga, TN forms the focal area of lake sturgeon reintroduction in the Southeastern U.S. (SLSWG 2013), although the Upper Cumberland River in Kentucky and the Coosa River in Georgia are stocked and monitored annually as well. Ft. Loudoun Reservoir is located on the Tennessee River near Knoxville, and is the uppermost of nine Tennessee Valley Authority (TVA) reservoirs that form a continuous navigable channel from Knoxville downstream to Paducah, Kentucky. Within the central portion of Ft. Loudoun Reservoir, a reach of habitat (Figs. 1, 2 and 3) was chosen to carry out this study. Stretching from river kilometer (RKM) 1006 upstream to RKM 1019, this area was selected after analyzing habitat utilization data collected from a prior telemetry study that used sonic VEMCO transmitters to track movement of 42 lake sturgeon in the Upper Tennessee River (Saidak 2015). Movement data over two years revealed that tagged individuals reliably inhabited or otherwise repeatedly passed through this study area. Based on annual monitoring of the Upper Tennessee River by the U.S. Fish and Wildlife Service, the highest density of reintroduced lake sturgeon occurs in Ft. Loudoun Reservoir (M. Cantrell, U.S. Fish and Wildlife Service, unpublished data).

Benthic invertebrate sampling

To assess benthic prey availability for lake sturgeon in the Ft. Loudoun Reservoir study area, $305-\mathrm{mm}^{2}$ Peterson dredge samples were taken from the reservoir bottom. These locations were determined using a systematic sampling design whereby benthic dredges were taken at 3-5 points (depending on the width of the river) spaced equidistantly along each transect from bank to bank. A series of transects perpendicular to the river flow were distributed evenly between RKM 1006 and 1019, roughly $1 \mathrm{~km}$ apart (Fig. 1).

From the boat, the dredge was attached to $30 \mathrm{~m}$ of steel cord and deployed by a winch connected to a custom-made boom crane constructed of stainless steel. The sediment from each dredge sample was emptied into a large plastic tub and homogenized by hand. Three randomly chosen 1-L subsamples were selected and deposited into a sieve bucket equipped with $500-\mu \mathrm{m}$ wire mesh. Invertebrate specimens were retrieved with forceps and preserved in 70\% isopropanol. They were stored and identified at the University of Tennessee Fisheries Research Lab in Knoxville, TN. If samples contained an unusual amount of organic matter that made picking invertebrates difficult or time consuming in the field, these samples were placed in their entirety in $70 \%$ isopropanol and sorted in the laboratory. Samples were identified by the primary author (TMA) using the most current dichotomous keys. A quality assurance process was conducted by the second author (JBA) by identifying a random sample of $10 \%$ of invertebrate identifications to check that identifications agreed with that of the primary author.

A cumulative prey taxa-sample curve was calculated to determine if an adequate number of lake sturgeon diets were examined to fully assess the invertebrate prey base that may be encountered (Wolda 1981). An adequate number of diets were sampled when this curve reached an asymptote when charted against the number of diets examined. Dredge samples were taken seasonally (37 total) within the study area to account for phenological changes in prey availability as invertebrates metamorphose from aquatic immature forms to terrestrial adults. Two seasons were sampled and occurred during a) warm weather months (May-September) and b) cool weather months (October-April). Though the diet of lake sturgeon may be primarily composed of benthic invertebrates from fine sediments (e.g., silt, clay, sand), the prey base available on or near hard substrate was also considered.

To characterize the available hard surface invertebrate assemblage, $0.01-\mathrm{m}^{3}$ rock basket samplers filled with hard substrate (riprap, limestone, and clay tiles on the bottom) were deployed opportunistically in areas containing hard substrate. Naturally occurring hard substrates in the study area included bridge pilings, rocky cliffs, gravel, cobble, and boulders, generally occurring in 1-3 $\mathrm{m}$ of water. Cages remained in place for a one-month period, allowing invertebrates to passively colonize the substrate within the cages via drift or active movement from surrounding surfaces. Cages were then retrieved and processed in the field after slowly and carefully pulling up the rope to which each cage was fastened. Invertebrates were picked with forceps not only from the substrate contained within the cage, but also from the cage itself, which was placed on a large, plastic laboratory tray. Each piece of hard 
Fig. 1 A stretch of riverine habitat in Ft. Loudoun Reservoir, Tennessee on the Tennessee River, which is known to reliably harbor lake sturgeon (Acipenser fulvescnes) (Saidak 2015); cross hatches symbolize the entirety of the study area

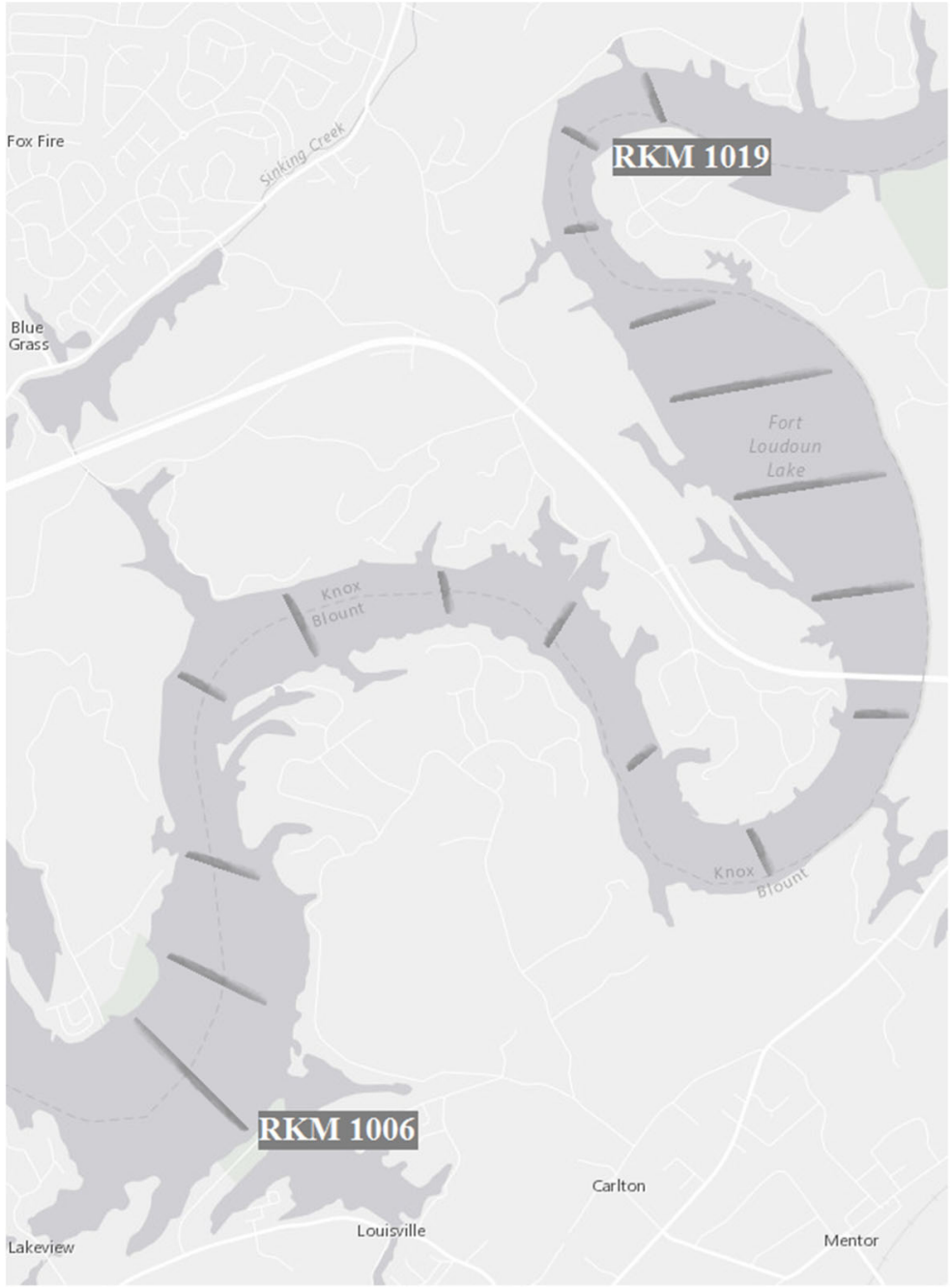

substrate was then placed in a separate laboratory tray as they were combed over for invertebrate specimens. These specimens were also preserved in $70 \%$ isopropanol, identified by TMA using the most current dichotomous keys, and passed through a quality assurance procedure administered by JBA.

\section{Lake sturgeon sampling}

To sample lake sturgeon, 8 trot-lines ( $91 \mathrm{~m}$ nylon line with 100 equally spaced J-hooks) baited with $2-\mathrm{cm}^{2}$ cut buffalofish (Ictiobus sp.) and common carp (Cyprinus carpio) were evenly spaced at $150 \mathrm{~m}$ apart on the reservoir bottom overnight (approximately 15-h soak). Multiple nights were spent sampling until the entire reach was covered during each season. Gastric lavage and a colonic flush were used to retrieve prey items from sedated lake sturgeon in cool months. To limit undue stress to fish sampled in the warm season, only the colonic flush technique was administered to expedite the processing time. Before performing gastric lavage and colonic flush techniques, specimens were sedated using $100 \mathrm{mg} / \mathrm{L}$ of tricaine methanesulfonate for 2$4 \mathrm{~min}$. Gastric lavage is a traditional non-lethal method for examining the content of fish stomachs. We followed the technique developed specifically for sturgeons by Haley (1998), which focuses on minimizing the mortality risk associated with inadvertently spraying water into the swim bladder. Colonic flushing is a recent, safer method for examining fecal matter contained in the intestinal tract, whereby a bottle is filled with river water and the end gently inserted $30-50 \mathrm{~mm}$ through the anus 
Fig. 2 Invertebrate taxa available to lake sturgeon (Acipenser fulvescens) in both the benthos and on hard substrate in Ft. Loudoun Reservoir during cooler months (October-April)

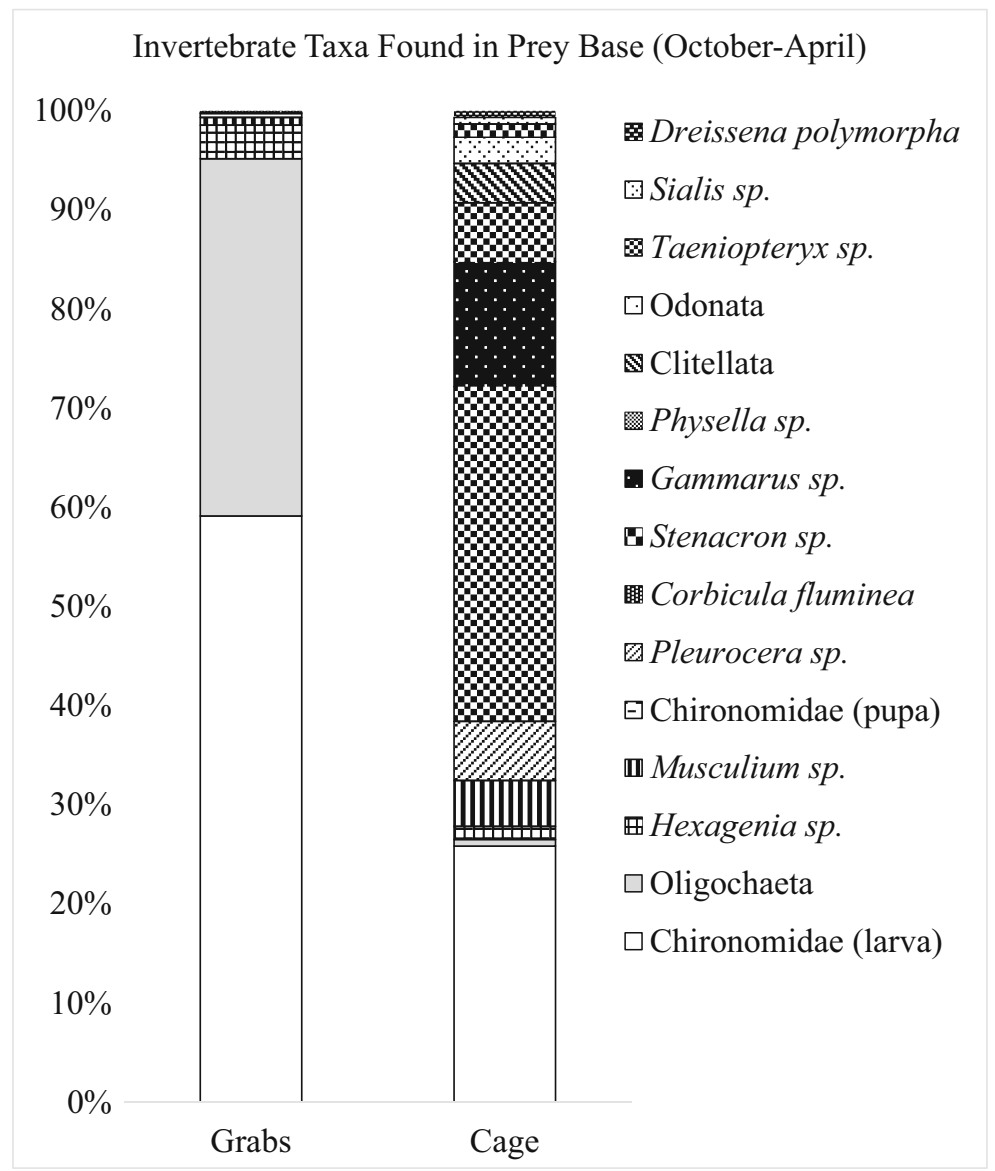

and into the colon. This method was developed successfully for pallid sturgeon (Scaphirhynchus albus) and shovelnose sturgeon (S. platorynchus) in the Mississippi River by Hoover et al. (2007). The bottle is gently squeezed in short pulses, and feces expelled into a dissecting pan. The colon is flushed until the expelled water is clear, generally a $15-30$ s process. Diet contents were strained in a 500- $\mu \mathrm{m}$ mesh sieve, picked, and preserved in $70 \%$ ethanol for later identification in the lab.

Although passive sampling gear such as baited trotlines can potentially bias prey selection studies, due to biased fish size captures and the tendency for fish to be hungry prior to be captured, the lake sturgeon in our study had very full colons and most stomachs had prey with similar items to that of colons. In addition, size and age distribution of our lake sturgeon was likely not biased since all year classes have been sampled using this technique since reintroduction began (M. Cantrell, U.S. Fish and Wildlife Service, unpublished data), and our size ranges were well within the range of all sizes and ages sampled during the annual trotline monitoring effort. Total lengths (TL) of our fish were $22-83 \mathrm{~cm}$ (mean TL $=69 \mathrm{~cm}$ ), and wet weights were $0.1-4.3 \mathrm{~kg}$ (mean weight $=1.7 \mathrm{~kg}$ ). Till now, the maximum length of reintroduced lake sturgeon in the Tennessee River system since trot-line sampling began has been $130 \mathrm{~cm}$ TL and $14.5 \mathrm{~kg}$; the oldest fish sampled to date has been 15 years, which is the original stocked year-class (M. Cantrell, U.S. Fish and Wildlife Service, unpublished data). Thus, the reintroduced Southeastern U.S. population is much younger and smaller than the Northern U.S. and Canadian populations. Other sampling techniques have been tried in this system by the U.S. Fish and Wildlife Service and TVA, but they have failed to effectively capture reintroduced lake sturgeon, including gill nets and electroshocking, thus the trot-line gear has been the accepted sampling method to monitor the recovery of the stock. 
Fig. 3 Invertebrate taxa available to lake sturgeon (Acipenser fulvescens) in both the benthos and on hard substrate in Ft. Loudoun Reservoir during warmer months (MaySeptember)

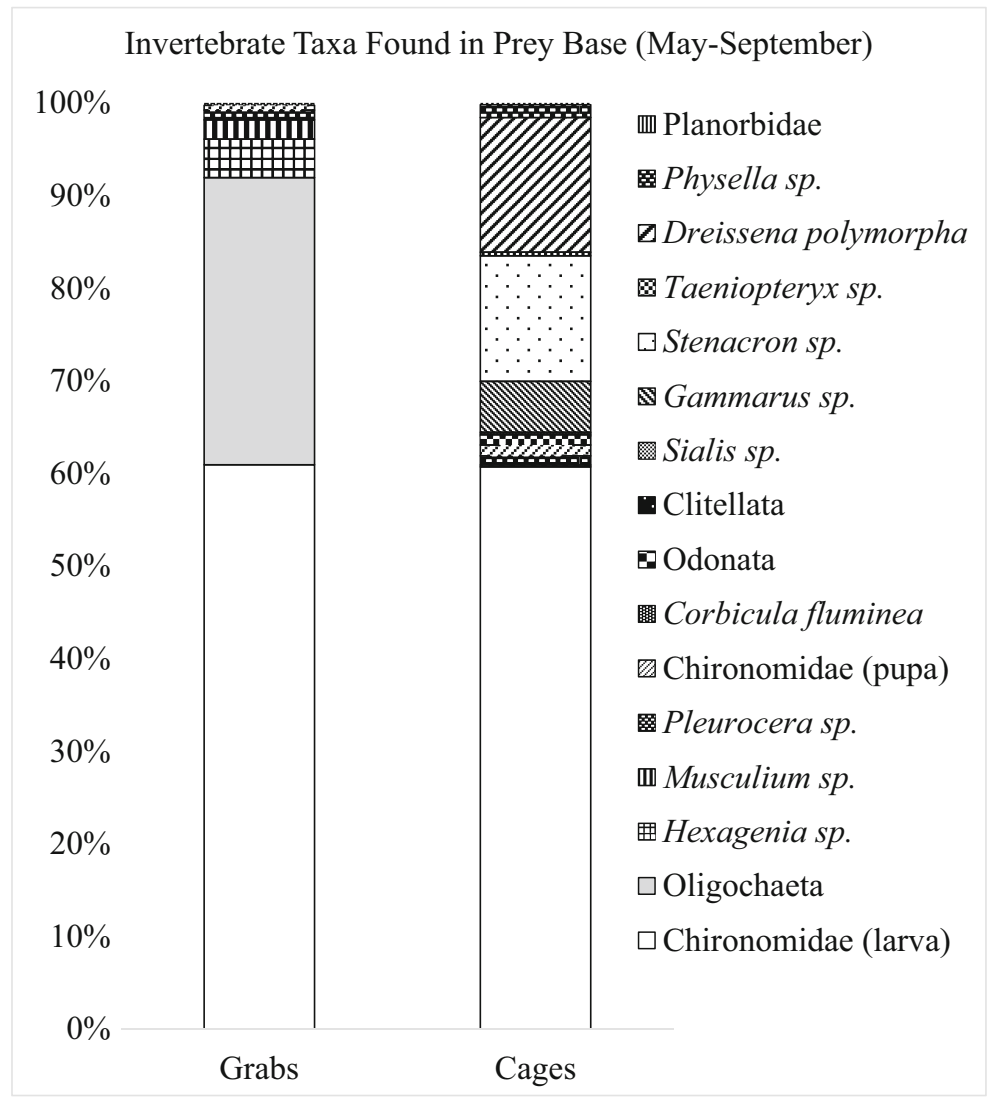

\section{Statistical analyses}

Following the methods of Alford and Beckett (2007), foraging mode was determined by comparing the relative abundances (i.e., percent composition by number) of invertebrate taxa in the gut contents of all lake sturgeon combined by season to the relative abundances of the same invertebrate taxa collected from the resource base. The resource bases sampled included benthic sediment predominately composed of silt and clay and hard artificial substrates from rock cages. Levins' niche breadth index (NB) was used to determine if lake sturgeon in Ft. Loudoun Reservoir fed on a relatively large or small array of prey taxa (Levins 1969; Wolda 1981). The equation is:

$\mathrm{NB}=1 /\left(\mathrm{s}^{*} \Sigma \mathrm{r}_{i}^{2}\right)$,

where "s" is taxa richness and " $r_{i}$ " is the relative abundance of taxon " $i$ " found in the diet of the all lake sturgeon sampled for a particular season. Values of NB discern specialists $(\mathrm{NB}=1 / \mathrm{s})$ from generalists $(\mathrm{NB}=1.0)$. Because using NB alone does not take available prey into consideration, niche breadth and proportional similarity should be used together to obtain a more accurate dietary assessment. Therefore, proportional similarity (PS) and NB were used in conjunction to determine the foraging mode of the Ft. Loudoun lake sturgeon population by season and type of resource base. The equation for PS is as follows:

$\mathrm{PS}=1-0.5 \Sigma\left|\mathrm{r}_{i}-\mathrm{q}_{i}\right|$,

where ' $r_{i}$ ' is the seasonal relative abundance of prey taxon ' $i$ ' found in the lake sturgeon diet, and ' $\mathrm{q}_{i}$ ' is the relative abundance of the same prey taxon found in the prey base for the same season; separate calculations were performed for the benthic grab and the rock cage resource bases. To identify prey taxa that were selected or not selected, Manly's index was used (Manly et al. 1993). Krebs (1989) describes Manly's index as the best index for 
describing resource preferences by populations. The equation for Manly's index is as follows:

$$
\alpha_{i}=\mathrm{r}_{i} / \mathrm{q}_{i}\left[1 / \Sigma\left(\mathrm{r}_{i} / \mathrm{q}_{i}\right)\right]
$$

The equation utilizes the number of prey taxa (i.e., richness) available in the resource base (symbolized by ' $m$ '). A value less than $1 / \mathrm{m}$ indicates a prey taxon that was consumed disproportionately less than its relative abundance in the resource base. Values approaching $1 / \mathrm{m}$ indicate that a prey taxon was consumed in direct proportion to its availability, and values greater than $1 / \mathrm{m}$ indicate a prey taxon that was consumed disproportionately more than its relative abundance in the resource base, with values near 1.0 indicating stronger selection of a prey taxon. To assess precision of the PS and NB estimates, a jacknife resampling technique was used to calculate $95 \%$ confidence intervals.

\section{Results}

Descriptions of diet and resource base

A total of 32 lake sturgeon were sampled by trotlines in Ft. Loudoun Reservoir (30 in the fall 2014, two in the summer 2015). Of these, 28 fish (88\%) had diet contents either in the stomach (gastric lavage) or intestine (colonic flush). We identified a total of 6581 invertebrates from lake sturgeon diets between cool (6416) and warm months (165). Chironomid taxa (Order Diptera) were found in all sturgeon diets (Table 1), while Hexagenia sp., Ceratopogonidae larvae, and Chaoborus sp. were also frequently consumed (frequency of occurrence $>50 \%$ ). The invertebrate taxa found in cool month diets were comprised of nine families and 14 genera (Table 2), while warm season diets consisted of three families and seven genera (Table 3).

Based on the prey taxa-sample curve (Fig. 4), we concluded that an adequate number of sturgeon diets were sampled to fully assess prey composition. Chironomid larvae dominated the percent composition of lake sturgeon diets during the cool ( $96 \%$ by number) and warm months (93\%) (Fig. 5). Other invertebrate taxa that contributed to lake sturgeon diets in the cooler months, albeit to a much lesser degree, included burrowing mayfly nymphs (Hexagenia sp., 1\%) and chironmid pupae (1\%). The two fish sampled during the summer fed almost exclusively on chironomid larvae $(93 \%)$, though chironomid pupae also contributed to the relative abundance (4\%) along with burrowing mayfly nymphs (Hexagenia sp., 1\%).

From the resource base we identified a total of 1667 invertebrates between cool (775) (Fig. 2) and warm months (892) (Fig. 3). The invertebrate taxa found in the cool season prey base consisted of 19 families and 40 genera (Table 2), while the warm season prey base consisted of 15 families and 18 genera (Table 3). A total of 83 benthic dredge samples were taken between cool (37 samples) and warm (46 samples) months. During cool months the benthic prey base was comprised primarily of chironomid larvae, oligochaetes, and burrowing mayfly nymphs (Hexagenia sp.), making up $97 \%$ of all invertebrates by number (Table 2). During warm months the benthic prey base was comprised mostly of chironomid larvae, oligochaetes, burrowing

Table 1 Frequency of occurrence for each taxon consumed by lake sturgeon (Acipenser fulvescens) $(N=30$ gastric lavage or colonic flushes) that contained prey during cool months (October-April); data were insufficient for warmer months (May-September)

\begin{tabular}{|c|c|c|c|c|}
\hline Class & Order & Family & Genus-Species & $\%$ Occurrence \\
\hline Insecta & Diptera & Ceratopogonidae & & 63 \\
\hline Insecta & Diptera & Chaoberidae & Chaoberus & 53 \\
\hline Insecta & Diptera & Chironomidae (larva) & & 100 \\
\hline Insecta & Diptera & Chironomidae (pupa) & & 17 \\
\hline Insecta & Ephemeroptera & Ephemeridae & Hexagenia & 67 \\
\hline Bivalvia & Veneroida & Pisidiidae & Musculium & 17 \\
\hline Bivalvia & Veneroida & Cyrenidae & Corbicula fluminea & 7 \\
\hline Nematoda & & & & 3 \\
\hline Oligochaeta & & & & 23 \\
\hline
\end{tabular}


Table 2 Percent composition by number for each invertebrate taxon in the diet of lake sturgeon, benthic grab, and rock cage samples from Fort Loudoun Reservoir, Tennessee (cool season, October-April)

\begin{tabular}{|c|c|c|c|c|c|c|}
\hline Class & Order & Family & Genus-Species & Diet & Grabs & Cages \\
\hline Insecta & Diptera & Chironomidae & Chironomus & 72.2 & 41.6 & 6.0 \\
\hline Insecta & Diptera & Chironomidae & Coelatanypus & 17.7 & 4.1 & 0.0 \\
\hline Insecta & Diptera & Chironomidae & Ablabesmyia & 3.0 & 2.7 & 0.0 \\
\hline Insecta & Diptera & Chironomidae & Procaldius & 1.0 & $<1.0$ & 1.0 \\
\hline Insecta & Diptera & Chironomidae & Cryptochironomus & 2.0 & 1.0 & 0.0 \\
\hline Insecta & Diptera & Ceratopogonidae & & $<1.0$ & 0.0 & 0.0 \\
\hline Insecta & Diptera & Chaoboridae & Chaoborus & 1.0 & 0.0 & 0.0 \\
\hline Insecta & Ephemeroptera & Ephemeridae & Hexagenia & 1.0 & 4.1 & 1.3 \\
\hline Insecta & Diptera & Chironomidae (pupae) & & 1.0 & $<1.0$ & 0.0 \\
\hline Bivalvia & Veneroida & Pisidiidae & Musculium & $<1.0$ & 1.0 & 4.7 \\
\hline Bivalvia & Veneroida & Cyrenidae & Corbicula fluminea & 1.0 & $<1.0$ & 0 \\
\hline Nematoda & & & & $<1.0$ & 0.0 & 0.0 \\
\hline Oligochaeta & & & & $<1.0$ & 44.2 & 1.0 \\
\hline Insecta & Diptera & Chironomidae & Goeldichironomus & 0.0 & 0.0 & 1.0 \\
\hline Insecta & Diptera & Chironomidae & Cladotanytarsus & 0.0 & 0.0 & 1.0 \\
\hline Insecta & Diptera & Chironomidae & Rheotanytarsus & 0.0 & 0.0 & 1.0 \\
\hline Insecta & Diptera & Chironomidae & Glyptotendipes & 0.0 & 0.0 & 1.0 \\
\hline Insecta & Diptera & Chironomidae & Cardiocladius & 0.0 & 0.0 & 1.3 \\
\hline Insecta & Diptera & Chironomidae & Unidentifiable & 0.0 & 0.0 & 1.3 \\
\hline Insecta & Diptera & Chironomidae & Chaetocladius & 0.0 & 0.0 & 2.0 \\
\hline Insecta & Diptera & Chironomidae & Tvetenia & 0.0 & 0.0 & 1.0 \\
\hline Insecta & Diptera & Chironomidae & Zalutschia & 0.0 & 0.0 & 1.0 \\
\hline Insecta & Diptera & Chironomidae & Metriocnemus & 0.0 & 0.0 & 1.0 \\
\hline Insecta & Diptera & Chironomidae & Eukiefferiella & 0.0 & 0.0 & 2.7 \\
\hline Insecta & Diptera & Chironomidae & Pseudochironomus & 0.0 & 0.0 & 1.0 \\
\hline Insecta & Diptera & Chironomidae & Cricotopus & 0.0 & 0.0 & 2.6 \\
\hline Insecta & Diptera & Chironomidae & Orthocladius & 0.0 & 0.0 & 2.0 \\
\hline Insecta & Diptera & Chironomidae & Beardius & 0.0 & 0.0 & 1.0 \\
\hline Insecta & Diptera & Chironomidae & Neozavrelia & 0.0 & 0.0 & 1.0 \\
\hline Insecta & Odonata & & & 0.0 & 0.0 & 2.7 \\
\hline Clitellata & & & & 0.0 & 0.0 & 4.0 \\
\hline Gastropoda & Sorbeoconcha & Pleuroceridae & Pleurocera & $<1.0$ & 0.0 & 6.0 \\
\hline Insecta & Megaloptera & Sialidae & Sialis & 0.0 & 0.0 & 1.0 \\
\hline Malacostraca & Amphipoda & Gammaridae & Gammarus & 0.0 & 0.0 & 12.7 \\
\hline Insecta & Ephemeroptera & Heptageniidae & Stenacron & 0.0 & 0.0 & 34.0 \\
\hline Insecta & Plecoptera & Taeniopterygidae & Taeniopteryx & 0.0 & 0.0 & 1.3 \\
\hline Bivalvia & Veneroida & Dreissenidae & Dreissena polymorpha & 0.0 & 0.0 & 1.0 \\
\hline Gastropoda & Basommatophora & Physidae & Physella & 0.0 & 0.0 & 6.0 \\
\hline
\end{tabular}

mayfly nymphs (Hexagenia sp.), fingernail clams (Musculium sp.), and hornsnails (Pleurocera sp.), which comprised $98 \%$ of all invertebrates (Table 3). Rock cages were deployed a total of 28 times between cool
(17 deployments) and warm (11 deployments) months. All but one of the cages were deployed for a month before being retrieved and processed. The one unprocessed cage was vandalized and lost to the bottom of the 
Table 3 Percent composition by number for each invertebrate taxon in the diet of lake sturgeon, benthic grab, and rock cage samples from Fort Loudoun Reservoir, Tennessee (warm season, May-September)

\begin{tabular}{|c|c|c|c|c|c|c|}
\hline Class & Order & Family & Genus-Species & Diet & Grabs & Cages \\
\hline Insecta & Diptera & Chironomidae & Chironomus & 47.9 & 52.6 & 0.0 \\
\hline Insecta & Diptera & Chironomidae & Coelatanypus & 10.9 & 4.7 & 0.0 \\
\hline Insecta & Diptera & Chironomidae & Cryptochironomus & 15.1 & 1.3 & 0.0 \\
\hline Insecta & Diptera & Chironomidae & Ablabesmyia & 19.4 & $<1.0$ & 0.0 \\
\hline Insecta & Diptera & Chironomidae & Ablabesmyia sp. II & 0.0 & 0.0 & 2.2 \\
\hline Insecta & Diptera & Chironomidae & Glyptodendipes & 0 & 0 & 56.3 \\
\hline Insecta & Diptera & Chironomidae & Dicrotendipes & 0.0 & 0.0 & 1.0 \\
\hline Insecta & Diptera & Chironomidae & Endochironomus & 0.0 & 0.0 & $<1.0$ \\
\hline Clitella & Rhynchobdellida & Glossiphoniidae & & 0.0 & 0.0 & $<1.0$ \\
\hline Insecta & Coleoptera & & & $<1.0$ & 0.0 & 0.0 \\
\hline Oligochaeta & & & & 0.0 & 31.1 & 0.0 \\
\hline Insecta & Odonata & & & 0.0 & 0.0 & $<1.0$ \\
\hline Clitellata & & & & 0.0 & 0.0 & $<1.0$ \\
\hline Insecta & Ephemeroptera & Ephemeridae & Hexagenia & 1.0 & 4.2 & 0.0 \\
\hline Insecta & Diptera & Chironomidae (pupae) & & 4.2 & $<1.0$ & 1.0 \\
\hline Gastropoda & Sorbeoconcha & Pleuroceridae & Pleurocera & 0.0 & 1.0 & 1.0 \\
\hline Bivalvia & Veneroida & Pisidiidae & Musculium & 0.0 & 2.0 & $<1.0$ \\
\hline Insecta & Megaloptera & Sialidae & Sialis & 0.0 & 0.0 & $<1.0$ \\
\hline Bivalvia & Veneroida & Cyrenidae & Corbicula fluminea & 0.0 & $<1.0$ & 0.0 \\
\hline Malacostraca & Amphipoda & Gammaridae & Gammarus & 0.0 & 0.0 & 5.5 \\
\hline Insecta & Ephemeroptera & Heptageniidae & Stenacron & 0.0 & 0.0 & 13.5 \\
\hline Insecta & Plecoptera & Taeniopterygidae & Taeniopteryx & 0.0 & 0.0 & $<1.0$ \\
\hline Bivalvia & Veneroida & Dreissenidae & Dreissena polymorpha & 0.0 & 0.0 & 14.5 \\
\hline Gastropoda & Basommatophora & Physidae & Physella & 0.0 & 0.0 & 1.0 \\
\hline Gastropoda & Basommatophora & Planorbidae & & 0.0 & 0.0 & $<1.0$ \\
\hline
\end{tabular}

reservoir. By number, $75 \%$ of invertebrates sampled were Hetpageniidae mayfly nymphs (Stenacron sp.), followed by chironomid larvae, amphipods (Gammarus sp.), and fingernail clams (Musculium sp.). Warm season rock cage samples were dominated by chironomid larvae, followed by zebra mussels (Dreissena polymorpha), Heptageniidae nymphs (Stenacron sp.), and amphipods (Gammarus sp.), comprising a total of $92 \%$ of all invertebrates.

\section{Foraging mode}

During cool months, the NB for lake sturgeon was 0.14 , suggesting a specialist foraging niche (Fig. 6). Meanwhile, PS during cooler months was marginally low when comparing the diet to the prey taxa found in the benthic grabs (PS $=0.52$ ), but it was extremely low when comparing prey taxa collected from rock cages $(\mathrm{PS}=0.08)$. In concert with NB values, these PS values indicate lake sturgeon are selective foragers on a relatively narrow array of prey taxa. Although sample size was low $(N=2)$, warmer months saw a higher NB, suggesting lake sturgeon might employ a broader, more generalist feeding niche during the summer $(\mathrm{NB}=0.41)$. Nonetheless, a low PS value of 0.57 also suggests lake sturgeon fed selectively on invertebrate taxa from the muddy benthos and hard substrates (PS $=0.02$ ).

Manly's index (Table 4) identified prey taxa that were selected or not selected. During the cool season, lake sturgeon selected five genera of larval chironomids (Chironomus sp., Ablabesmyia sp., Procladius sp., Coelotanypus sp., and Cryptochironomus sp.), along with chironomid pupae and the Asian clam Corbicula fluminea. During warmer months, the two lake sturgeon 
Fig. 4 A prey taxa-sample curve revealing that an adequate number of lake sturgeon (Acipenser fulvescens) individuals ( $\mathrm{x}$ axis) were sampled in order to properly assess the cumulative number of invertebrate taxa consumed (y axis) (a trend line shows that the cumulative number of invertebrate taxa consumed, signified by grey x's, plateaus); only cool season fish (OctoberApril) were assessed, as warm season data (May-September) were insufficient

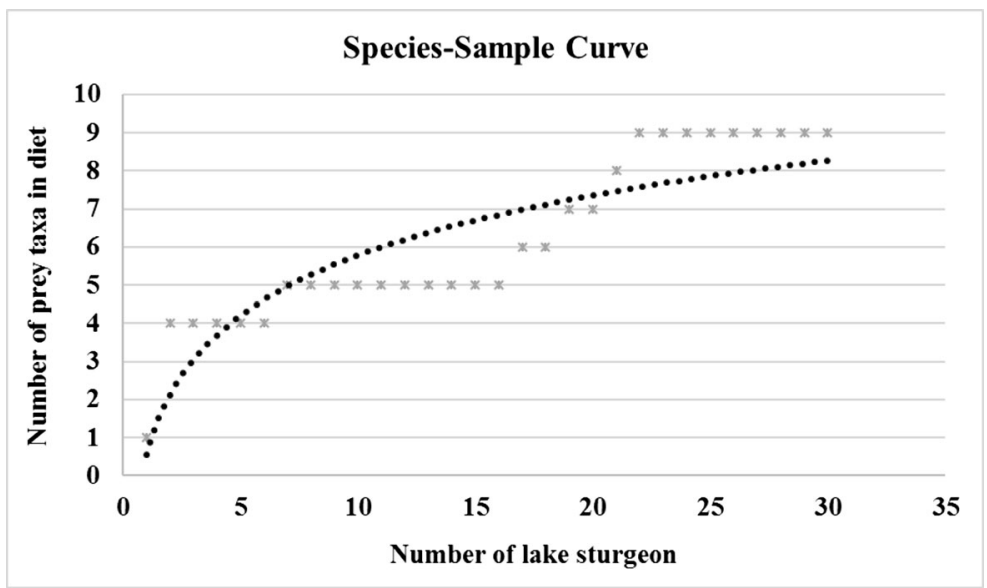

selected 3 genera of larval chironomids (Ablabesmyia sp., Coelotanypus sp., and Cryptochironomus sp.) and chironomid pupae.

\section{Discussion}

During cooler months, reintroduced juvenile lake sturgeon in Ft. Loudoun Reservoir tended to feed more like classic specialists, because they fed disproportionately more on chironomid larvae (96\%), even when that prey taxon was only available at a relative abundance of 50\% in the benthos and $25 \%$ on hard substrates, respectively. The only taxon that was available in relatively high abundance in the benthos (44\%) but consumed disproportionately less $(0.05 \%)$ was the Oligochaeta. During warmer months, though diet data was limited to two individuals, lake sturgeon also fed like specialists, again disproportionately feeding on chironomid larvae (93\%) even when their relative abundances in the benthos $(61 \%)$ and rock cages $(61 \%)$ were substantially less. Oligochaetes were again available at a relatively high
Fig. 5 Invertebrate taxa recovered from the stomachs and colons of lake sturgeon (Acipenser fulvescens) from Ft. Loudoun Reservoir during cool (October-April) and warm (MaySeptember) months (displayed as relative abundance)

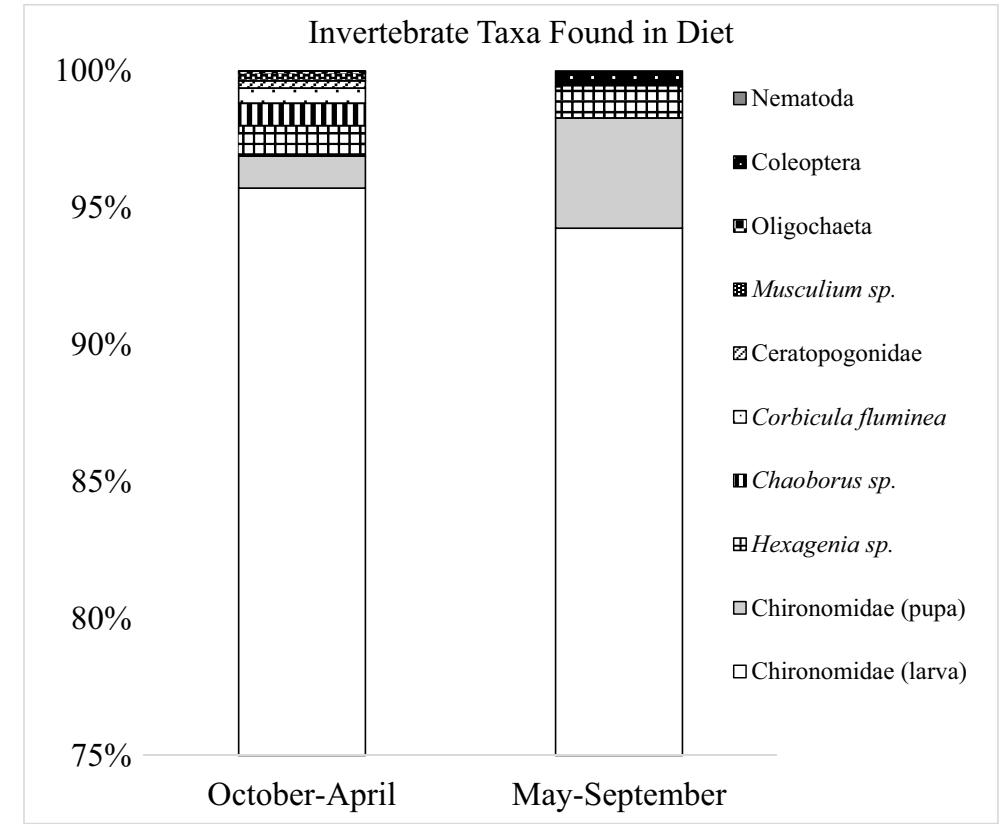




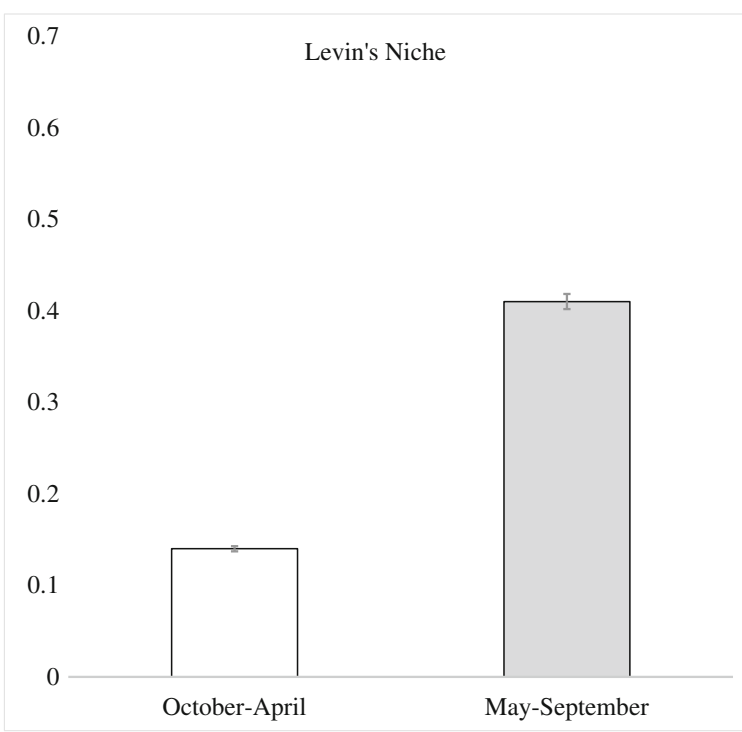

Fig. 6 Levin's niche breadth (NB) indicates whether lake sturgeon (Acipenser fulvescens) in Ft. Loudoun Reservoir utilize a relatively narrow (close to 0 ) or wide (approaching 1 ) niche

abundance (31\%), but no oligochaetes were found in the two sturgeon diets. Likewise, the most abundant chironomid larva found in the rock cages was Glyptotendipes sp. (58\% composition), but it was never encountered in the diet. Along with the lack of Heptageniidae mayflies in the diet (14\% in rock cages), there is no evidence to suggest that juvenile lake sturgeon in Ft. Loudoun reservoir utilize hard substrates as a prey base.

When describing the foraging mode of lake sturgeon, it is important to consider the taxonomic scale at which prey items are identified. Identifying prey items to family, albeit less time consuming and labor intensive, can potentially mislead the investigator into concluding that lake sturgeon are generalists, as other diet studies have suggested. Our results suggest that lake sturgeon in Ft. Loudoun Reservoir forage selectively on certain seasonally available chironomid genera, whereas other available genera were avoided. The behaviors of certain larval chironomids might make them more prone to predation. Tube-dwellers like the Chironomus sp. that spent more time outside of their tube feeding may have been more susceptible to predation (Hershey 1987). High population densities of Chironomus sp. only transpire in sediments that are deep enough to allow construction of extensive vertical tubes (Pinder 1995), which Ft. Loudoun Reservoir maintains in abundance. These tubes regularly protrude $2-3 \mathrm{~cm}$ above the level of the sediment, making them an easy target for lake sturgeon cruising above the benthos in search of attainable food items. Also, predatory chironomids such as Coelotanypus, Ablabesmyia, Cryptochironomus, and Procladius spp. may have made themselves available to predation by spending a considerable amount of time outside of their tubes crawling over the substrate in search of prey items (typically other chironomids).

Perhaps the most unanticipated aspect of the diet data is the general lack of oligochaetes found in lake sturgeon stomachs and/or colons. Oligochaetes can contribute significantly to the relative abundance of lake sturgeon diets in other geographical areas. For example, Choudhury et al. (1996) found oligochaetes to be the second most numerous prey item found in lake sturgeon stomachs in Lake Winnebago, Wisconsin. Oligochaetes were quite plentiful in Ft. Loudoun Reservoir; cooler months saw a relative abundance of $44 \%$ in the benthos while warmer months maintained a relative abundance of $31 \%$. In contrast, the cool season saw a total of two oligochaetes in sturgeon stomachs and only one in the colon. No oligochaetes were found in either of the fish sampled in July 2015. Oligochaetes are the only completely softbodied organisms consumed by lake sturgeon in Ft. Loudoun Reservoir, and are a potentially nutritive prey item. It can be presumed that soft-bodied organisms

Table 4 The proportional compositions from lake sturgeon diets $\left(\mathrm{r}_{i}\right)$ and the resource base $\left(\mathrm{q}_{i}\right)$ in Ft. Loudoun Reservoir are shown. Manly's index values (훼 ${ }_{i}$ greater than $1 / \mathrm{m}$ denote selective predation by lake sturgeon on a prey taxon.

\begin{tabular}{lccr}
\hline Invertebrate Prey & & $\mathrm{r}_{i}$ & \multicolumn{1}{c}{$\mathrm{q}_{i}$} \\
\hline Cool months $(1 / \mathrm{m}=1 / 39=0.026$ & & \\
Chironomus $\mathrm{sp}$. & 0.10 & 0.72 & 0.35 \\
Coelotanypus $\mathrm{sp}$. & 0.25 & 0.18 & 0.03 \\
Ablabesmyia sp. & 0.06 & 0.03 & 0.02 \\
Procladius sp. & 0.10 & 0.01 & 0.01 \\
Cryptochironomus sp. & 0.11 & 0.02 & 0.01 \\
Chironomidae (pupa) & 0.15 & 0.01 & $<0.01$ \\
Corbicula fluminea & 0.21 & 0.01 & $<0.01$ \\
Warm months $(1 / \mathrm{m}=1 / 27=0.037$ & & \\
Coelotanypus sp. & 0.06 & 0.11 & 0.02 \\
Ablabesmyia sp. & 0.59 & 0.19 & $<0.01$ \\
Cryptochironomus sp. & 0.28 & 0.15 & 0.01 \\
Chironomidae (pupa) & 0.05 & 0.04 & 0.01 \\
\hline
\end{tabular}

The value of $1 / \mathrm{m}(\mathrm{m}=$ taxa richness $)$ indicates a taxon that is not selected or avoided. Values below $1 / \mathrm{m}$ mean a taxon is avoided, and values above are taxa that are selected 
might be digested more quickly, suggesting that oligochaetes are consumed more regularly by lake sturgeon even though they fail to make their way through the entire digestive system relatively intact. But this impression is not befitting since we observed live chironomids extracted from sturgeon colons on multiple occasions. Furthermore, oligochaetes were found in previous studies to make a considerable contribution to the relative abundance of prey items after they most certainly passed through lake sturgeon digestive systems intact. A better explanation could be that the preferred burrowing depths of oligochaete taxa in Ft. Loudoun Reservoir put them out of reach of the comparatively small lake sturgeons' protrusible mouths. This could mean that oligochaetes are not functionally available to lake sturgeon in Ft. Loudoun Reservoir. After inferring that lake sturgeon in Ft. Loudoun Reservoir prefer to forage from within the benthos (see Fig. 7), one might speculate as to why this is so. Seeing as previous studies found that juvenile lake sturgeon from northern latitudes rely heavily on larval chironomids, ephemeropterans, and annelids from a mixture of substrate particles (Kempinger 1996; Chiasson et al. 1997), these prey items can be encountered over flat, expansive, and homogenous fine sediments in Ft. Loudoun Reservoir. Novel prey taxa retrieved from our rock cages (i.e., prey taxa found in rock cages but not the

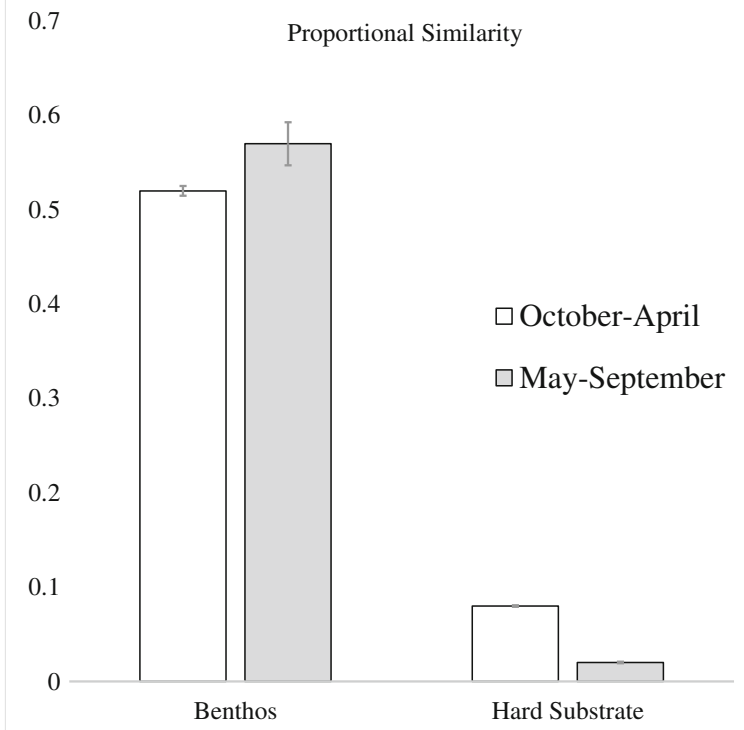

Fig. 7 Proportional Similarity (PS) compares the invertebrate taxa composition found in the diet of lake sturgeon (Acipenser fulvescens) to the invertebrate taxa composition found in the prey base in Ft. Loudoun Reservoir (closer to 0 is less similar, closer to 1 is more similar) benthic grabs) were altogether missing froml sturgeon diets. Though a suitable prey base is available on a variety of hard substrates that include: rip-rap along waterfront properties, bridge pilings and, limestone cliffs; it would likely be more energetically taxing for sturgeon to pursue these prey items. This is the likely explanation as to why the benthos is the preferred habitat for foraging. Also, hard substrate habitats in Ft. Loudoun Reservoir tend to be more patchily distributed and are thus encountered less frequently by lake sturgeon.

A thorough, quantitative characterization of benthic substrate was not considered, though the general composition of each grab was documented. Of the 83 total benthic grabs retrieved, 63 of them were composed of fine silt, five contained considerable amounts of fine particulate organic material, five contained minimal fine particulate organic matter, five were composed of a mixture of cobble and gravel, two were hard-packed clay, two were primarily composed of sand, one was exposed bedrock, and one was an entire boulder approximately $65 \mathrm{~cm}$ in diameter. Previous studies have investigated lake sturgeon diet in the northern reaches of this species' expansive range; generally, these studies have concluded that A. fulvescens is an opportunistic, benthic feeder (Chiasson et al. 1997; Nilo et al. 2006) that preys on a wide variety of taxa. Nonetheless, diets of these populations were similar to our findings at a broad taxonomic scale. For example, Northern U.S. and Canadian lake sturgeon populations feed on chironomids, snails, zebra mussels, ephemeropterans and oligochaetes (Choudhury et al. 1996; Jackson et al. 2002; Barth et al. 2013). In contrast to our findings, amphipods and trichopterans were also consumed heavily in Northern U.S. and Canadian lake sturgeon populations (Jackson et al. 2002; Barth et al. 2013). However, it is important to note that few of these studies compared lake sturgeon diet to the relative abundance of prey taxa available in the resource base, making it difficult or impossible to properly discern foraging patterns. Furthermore, even fewer diet studies have identified chironomid larvae to the genus/species level. We believe that, in addition to a systematic assessment of prey availability, identifying chironomid larvae to genus helps to accurately determine foraging mode for suctionfeeding, benthic invertivores (Alford and Beckett 2007), especially when larval chironomids are consumed so disproportionately to other families of prey items.

The reintroduction of lake sturgeon into the Southeastern U.S. has caused some concern regarding the possibility of the reintroduced fish consuming imperiled 
native mussels in the family Unionidae. There are common unionid mussels that are flourishing in the impounded reservoir habitats of the Tennessee, Cumberland, and Coosa River systems (pers. comm. G. Dinkins, Curator of the Parmalee Mollusk Collection, McClung Museum of Natural History and Culture, University of Tennessee). However, we speculate that lake sturgeon in Ft. Loudoun Reservoir at present are too small and thus gape-limited regarding adult unionid mussel consumption (though they would certainly be capable of preying upon juveniles). We found only nonnative fingernail clams and Asian clams in our lake sturgeon diets. Of the 36 Corbicula clams consumed, 33 were found in 2 fish that were the third and fourth largest fish sampled (71 $\mathrm{cm} \mathrm{TL)}$. It may be possible that larger lake sturgeon downstream of Ft. Loudoun Reservoir could consume native mussels, but this could only be investigated with future diet studies in other reservoirs that contain larger/older fish.

Although previous studies have found evidence of lake sturgeon feeding upon both adult and age- 0 fish (Jackson et al. 2002), we found no evidence of piscivory exhibited by lake sturgeon in Ft. Loudoun Reservoir, which would come in the form of fish scales, otoliths, or identifiable body parts or even whole organisms. We did, however, regularly find considerable amounts of fine sediment in the colons of sampled lake sturgeon. This could provide an opportunity for toxins to bioaccumulate in lake sturgeon over the length of their considerable life spans, and is worthy of further study.

Of the 32 fish sampled across seasons, the gastric lavage technique was not administered to a total of eight fish (six during cool seasons, two during the summer). The colonic flush technique was not administered on two fish, both during the cool season. The fish sampled during the summer were intentionally not sampled for stomach content due to a perceived threat to the fishes' physiology, primarily because of elevated water temperatures. There were occasions when stomach and/or colon contents were empty. On 11 occasions stomach contents were empty, while on four occasions we found empty colons. It is possible that a specimen could have recently defecated (in the case of an empty colon) or not foraged recently (in the case of an empty stomach). Apart from one nematode found in the colons and zero in the stomachs, the same taxa were found in gastric lavage samples as those from the colonic flush samples, and they were in very similar proportions (both dominated by chironomids, followed by Hexagenia mayflies, then Asian clams).

Concern was expressed about sampling fish during summer months, and this was not taken lightly. The gastric lavage technique was waived in favor of the colonic flush technique, as it is generally a quicker process and less stressful for lake sturgeon specimens. After a three-day sampling effort in July, two fish were caught on trotlines. Diet data was gained from both fish and was quite valuable; to our knowledge, lake sturgeon diet had not been assessed during summer months in the extreme southern range of its distribution. This helped to dispel the notion that lake sturgeon minimize or even avoid feeding during the summer months. However, having only sampled two fish during warmer months, it is difficult to adequately infer any quantitative patterns regarding lake sturgeon ecology or behavior during summer months. We suggest further research be conducted on lake sturgeon diet during both cool and warm months in other reservoirs within the Upper Tennessee River System. Specifically, it would be insightful to assess the diet and prey availability for lake sturgeon in reservoirs farther downstream where lake sturgeon are larger (Saidak 2015) and where there may be less fine sediment. Noting that Ft. Loudoun Reservoir tends to harbor lake sturgeon on the smaller end of the spectrum, foraging habits of larger fish downstream could yield noticeably distinctive results. Our study cannot ascertain the foraging habits of the historic native stock that would have inhabited a free-flowing environment. We can only provide information on the diet patterns of this non-native genetic stock of lake sturgeon that now must reside in a highly regulated river system. Perhaps as fish disperse into the free-flowing tributaries of the Tennessee, Cumberland, and Coosa Rivers then we can more fully understand the foraging ecology of lake sturgeon at the southern end of their range.

Acknowledgements We thank Carlos Eschevarria, Brian Hickson, and Mark Cantrell from U.S. Fish and Wildlife Service for help in the field. Bernie Kuhajda from the Tennessee Aquarium Conservation Institute and Ben Keck from the University of Tennessee supplied profound academic guidance. Graduate students and research staff from the University of Tennessee that were instrumental in the field were Dan Walker, Meredith Harris, Christina Saidak, Joyce Coombs, Keith Garner, and Justin Wolbert. We 
thank two anonymous reviewers who provided very helpful comments. Funding was provided by the University of Tennessee Institute of Agriculture and Department of Forestry, Wildlife, and Fisheries. The field sampling was performed under the IACUC protocol \#2257-0414.

Open Access This article is distributed under the terms of the Creative Commons Attribution 4.0 International License (http:// creativecommons.org/licenses/by/4.0/), which permits unrestricted use, distribution, and reproduction in any medium, provided you give appropriate credit to the original author(s) and the source, provide a link to the Creative Commons license, and indicate if changes were made.

\section{References}

Alford JB, Beckett DC (2007) Selective predation by four darter (Percidae) species on larval chironomids (Diptera) from a Mississippi stream. Environ Biol Fish 78:353-364

Barth CC, Anderson WG, Peake SJ, Nelson P (2013) Seasonal variation in the diet of juvenile lake sturgeon, Acipenser fulvescens, Rafinesque, 1817, in the Winnipeg River, Manitoba, Canada. J ApplIchthyol 29(4):721-729

Bezold J, Peterson DL (2008) Assessment of lake sturgeon reintroduction in the Coosa River system, Georgia-Alabama. American fisheries society, symposium 62, Bethesda

Chiasson WB, Noakes DL, Beamish FW (1997) Habitat, benthic prey, and distribution of juvenile lake sturgeon (Acipenser fulvescens) in northern Ontario rivers. Can J Fish Aquat Sci 54(12):2866-2871

Chipps SR, Garvey JE (2007) Assessment of food habits and feeding patterns: analysis and interpretation of freshwater fisheries data. In: Brown M (ed) Analysis and interpretation of freshwater fisheries data. American Fisheries Society, Bethesda, pp 502-514

Choudhury A, Bruch R, Dick TA (1996) Helminths and food habits of lake sturgeon Acipenser fulvescens from the Lake Winnebago system, Wisconsin. Am Midl Nat 135(2):274282

Drauch AM, Rhodes OE Jr (2007) Genetic evaluation of the lake sturgeon reintroduction program in the Mississippi and Missouri rivers. N Am J Fish Manag 27:434-442

Finnoff D, Tschirhart J (2003) Protecting an endangered species while harvesting its prey in a general equilibrium ecosystem model. Land Econ 79(2):160-180

Haley N (1998) A gastric lavage technique for characterizing diets of sturgeons. N Am J Fish Manag 18:978-981

Harkness WJK (1923) The rate of growth and the food of the lake sturgeon (Acipenser rubicundus LeSueur). Ont Fish Res Lab 24(18):15-42

Harkness WJK, Dymond JR (1961) The lake sturgeon. Ontario Department of Lands and Forests, Toronto

Haxton T (2011) Depth selectivity and spatial distribution of juvenile lake sturgeon in a large, fragmented river. J Appl Ichthyol 27(2):45-52
Hershey AE (1987) Tubes and foraging behavior in larval Chironomidae: implications for predator avoidance. Oecologia 73:236-241

Higgins J, Brock W (1999) Overview of reservoir release improvements at 20 TVA dams. J Energ Eng-ASCE 125(1):117

Hoover JJ, George SG, Kilgore JK (2007) Diet of shovelnose sturgeon and pallid sturgeon in the free-flowing Mississippi River. J Appl Ichthyol 23:494-499

Jackson JR, Van De Valk AZ, Brooking TE, Van Keeken OA, Rudstam LG (2002) Growth and feeding dynamics of lake sturgeon, Acipenser fulvescens, in Oneida Lake, New York: results from the first five years of a restoration program. J Appl Ichthyol 18(4-6):439-443

Kempinger JJ (1996) Habitat, growth, and food of young lake sturgeon in Lake Winnebago system, Wisconsin. N Am J Fish Manag 16:102-114

Krebs CJ (1989) Ecological methodology. Harper and Row, New York

Lebreton GTO, Beamish FW (2005) Growth, bioenergetics and age. Fish Fisheries Serie 27:195-216

Levins R (1969) Some demographic and genetic consequences of environmental heterogeneity for biological control. Bull Entomol Soc Am 15:237-240

Manly, BFJ, McDonald LL, Thomas, DL (1993) Resource selection by animals: Statistical design and analysis for field studies. Chapman and Hall, London

Nilo P, Tremblay S, Bolon A, Dodson J, Dumont P, Fortin R (2006) Feeding ecology of juvenile lake sturgeon in the St. Lawrence River system. T Am Fish Soc 135(4):1044-1055

Peterson DL, Vecsei P (2004) Sturgeons and paddlefish of North America. Kluwer Academic Publishers, Dordrecht

Peterson DL, Vecsei P, Jennings CA (2007) Ecology and biology of the lake sturgeon: a synthesis of current knowledge of a threatened north American Acipenseridae. Rev Fish Biol Fish 17(1):59-76

Pinder LCV (1995) The habitats of chironomid larvae. In: Armitage P, Cranston PS, LCV P (eds) The Chironomidae. Chapman and Hall, London, p 123

Pollock MS, Carr M, Kreitals NM, Phillips ID (2015) Review of a species in peril: what we do not know about lake sturgeon may kill them. Environ Rev 23(1):30-43

Saidak CG (2015) Determination of dispersal patterns and characterization of important habitats for lake sturgeon restoration in the upper Tennessee River system. Thesis, University of Tennessee-Knoxville

SLSWG (Southeast Lake Sturgeon Working Group) (2013) Lake sturgeon management plan for the Tennessee and Cumberland Rivers. U.S. Fish and Wildlife Service, Warm Springs

Vander Zanden MJ, Shuter BJ, Lester NP, Rasmussen JB (2000) Within-and among-population variation in the trophic position of a pelagic predator, lake trout (Salvelinus namaycush). Can J Fish Aquat Sci 57(4):725-731

Vannote RL, Minshall GW, Cummins KW, Sedell JR, Cushing CE (1980) The river continuum concept. Can J Fish Aquat Sci 37(1):130-137

Wolda H (1981) Similarity indices, sample size and diversity. Oecologia 50(3):296-302 